\title{
Effect of endocervical inflammation on days to conception in dairy cows
}

\author{
L. Deguillaume, ${ }^{\star} † \ddagger$ A. Geffré,§ L. Desquilbet,\# A. Dizien, ${ }^{\star}$ S. Thoumire, $†$ C. Vornière, ${ }^{\star}$ F. Constant, ${ }^{\star} † \ddagger$ \\ R. Fournier, Il and S. Chastant-Maillard $\prod^{1}$ \\ *ENVA, Reproduction, 7 Avenue du Général de Gaulle, F-94700 Maisons-Alfort, France \\ †ENVA, UMR 1198 Biologie du Développement et Reproduction, 7 Avenue du Général de Gaulle, F-94700 Maisons-Alfort, France \\ †INRA, UMR 1198 Biologie du Développement et Reproduction, F-78350 Jouy-en-Josas, France \\ $\S E N V T$, Département des Sciences Cliniques, 23 chemin des Capelles, F-31076 Toulouse, France \\ \#ENVA, Epidémiologie des Maladies Animales et Infectieuses, 7 Avenue du Général de Gaulle, F-94704 Maisons-Alfort, France \\ IIMSD Animal Health, F-49071 Beaucouzé, France \\ IENVT, Reproduction, 23 chemin des Capelles, F-31076 Toulouse, France
}

\section{ABSTRACT}

In contrast to endometritis, now diagnosed by cytological examination, the effect of endocervical inflammation on reproductive performance has been inadequately investigated. In this study, endocervical and endometrial cytological specimens were collected from 168 Holstein cows between 21 and 60 days in milk (DIM) to investigate the prevalence of endocervical inflammation and effect on days to conception. Statistical analyses were stratified based on DIM at examination $(<35$ vs. $\geq 35$ DIM). Endocervical inflammation with $\geq 5 \%$ neutrophils before 35 DIM (disregarding the level of endometrial inflammation) was associated with decreased hazard of pregnancy within 300 DIM (adjusted hazard ratio, $0.4 ; 95 \%$ confidence interval: $0.3-0.8$ ). A decrease in hazard of pregnancy was observed when $>6 \%$ neutrophils were counted in endometrial smears (adjusted hazard ratio, 0.4; 95\% confidence interval: $0.2-0.7)$. The study suggested an additive effect of combined endocervical and endometrial inflammation on the hazard of pregnancy within 300 DIM. Using the thresholds of $5 \%$ neutrophils for the cervix and $6 \%$ neutrophils for the uterus, $11 \%$ of the cows examined before 35 DIM presented cervicitis only, $13 \%$ were affected by endometritis only, and $32 \%$ suffered from both endometrial and endocervical inflammation. The presence (absence) of cervicitis was not indicative of the presence (absence) of endometritis. This study showed that in addition to uterine inflammation, endocervical inflammation in early lactation affects conception. Thus, the global evaluation of genital tract health may be more beneficial for reproductive performance than that of endometrial inflammation.

Key words: cytology, endometritis, cervicitis, fertility

Received June 5, 2011.

Accepted December 14, 2011.

${ }^{1}$ Corresponding author: s.chastant@envt.fr

\section{INTRODUCTION}

The recovery of a healthy uterine environment after calving is a major limiting factor for bovine fertility. An increasing body of knowledge demonstrates that inflammation of the uterine mucosa evaluated by cytology around 30 DIM (from 20 to 60 DIM) is associated with impaired subsequent reproductive performance: reduction of pregnancy rate at first service (Gilbert et al., 2005; Barlund et al., 2008; Sheldon et al., 2008), decrease in pregnancy by 150 DIM (Gilbert et al., 2005; Barlund et al., 2008), increased median time to pregnancy (Sheldon et al., 2008), and increased risk of culling for infertility (LeBlanc, 2008). At endometrial cytology, a proportion of neutrophils $>3.5$ to $11 \%$ on specimens collected from 20 to 49 DIM is regarded as pathological (cytological endometritis; Barlund et al., 2008; Galvão et al., 2009; Dubuc et al., 2010a).

Ahmadi et al. (2006a) suggested that collection of an endocervical specimen in cows was an easy-to-perform alternative to an endometrial smear, even though they did not investigate the relationship between endocervical and uterine inflammation. Moreover, in contrast to endometritis, the effect of endocervical inflammation on reproductive performance has been inadequately investigated in dairy cows. To date, no cytological threshold has been proposed for endocervical inflammation and most studies on cervicitis were based on a clinical definition of this condition (Gloor, 1967; Stephens et al., 1986).

The main objectives were to determine the prevalence of endocervical inflammation as diagnosed by cytological examination and to evaluate its effect on days to conception in dairy cows. The secondary objectives were to characterize endocervical inflammation; that is, to identify the leukocyte sub-population involved and examine the relationship with ovarian cyclicity and endometrial inflammation. 


\section{MATERIALS AND METHODS}

\section{Animals}

The study was conducted between March 2007 and April 2008 in 3 commercial herds. Herd sizes were 102, 130, and 300 lactating Holstein cows. The milk yields were $24.2 \pm 8.7,25.0 \pm 2.6$, and $29.6 \pm 7.7 \mathrm{~kg} / \mathrm{cow}$ per day during the study period for herds 1,2 , and 3 , respectively. All lactating cows that were between 21 and 60 DIM ( $\mathrm{n}=168$ in total) were enrolled. No exclusion criteria were applied. The following postpartum events were recorded: calving date, calving difficulty, occurrence of twin birth, and diseases. Postpartum diseases were recorded as a single outcome that included retained placenta (i.e., failure to expel fetal membranes within $24 \mathrm{~h}$ of calving), metritis (i.e., fetid red-brown watery uterine discharge associated with signs of systemic illness within 21 DIM), milk fever, abomasal displacement, and clinical mastitis. Body condition score was recorded on a 5-point scale at examination (Edmonson et al., 1989).

\section{Cytological Examination}

On each cow, an endocervical specimen was collected, followed by an endometrial sample. Both endocervical and endometrial cytological specimens were collected using a cytobrush (Cytobrush Plus GT, Medscand Medical, Alcyon, France) modified for use in large animals (Kasimanickam et al., 2004). Briefly, the cytobrush was cut to approximately $9 \mathrm{~cm}$ in length and placed into the stainless steel tube of an insemination pipette $(45 \mathrm{~cm}$ long and $4.1 \mathrm{~mm}$ in diameter; Kombicolor, IMV Technologies, L'Aigle, France). The cytobrush was inserted $4.5 \mathrm{~cm}$ into the tube and fixed with Adheroplaste (BSN Medical, Vibraye, France). The device was protected by a plastic sheath (44 cm long, IMV Technologies) and placed into a sanitary plastic sleeve (IMV Technologies).

Two devices were used for each cow. Endocervical sampling was performed by inserting the lubricated (paraffin oil, Esprit Composite, Paris, France) instrument through the vagina into the external cervical os. The device was pushed forward as far as the second cervical ring. The sanitary sleeve was then punctured and the plastic sheath retracted to expose the cytobrush. Once the brush had been rolled onto the cervical wall, it was pulled back into the plastic sheath and removed from the vagina. Smears were processed immediately by rolling the brush on a slide and immediately fixed (CytoRAL, CML, Nemours, France). Endometrial sampling was performed in a similar way, as described by Kasimanickam et al. (2004), with a second lubricated instrument introduced into the uterine body by cervical catheterization. The sanitary sleeve was broken after the cervical catheterization, into the uterine body, before rolling the cytobrush on the mucosa.

The specimens were stained with May-Grünwald-Giemsa (Aerospray automate; Wescor, Kitvia, Labarthe Inard, France). After assessment of the homogeneity of the slide at low power magnification $(100 \times)$, a cytological examination was performed at high power magnification $(1,000 \times)$. Two hundred nucleated cells were counted and classified as epithelial cells, neutrophils, eosinophils, basophils, lymphocytes/plasma cells, and monocytes/macrophages (Couto and Hughes, 1984; Kramer, 2000; Jones and Allison, 2007). Large epithelial cell clusters and lysed cells were not included in the differential count. The results were expressed as percentage of neutrophils over the total number of cells counted $(\% \mathbf{N})$. The presence of a hemorrhagic background, band neutrophils, or bacteria (free or intracellular) was evaluated qualitatively.

\section{Ovarian Cyclicity}

A blood sample was collected into sterile tubes (with 18-gauge needles and 5-mL vacuum tubes) with EDTA by coccygeal vessel puncture. In the laboratory, the tubes were centrifuged at $4,000 \times g$ for $5 \mathrm{~min}$ and the plasma was frozen at $-20^{\circ} \mathrm{C}$ until the progesterone assay (electro-chemiluminescence automated ELISA technique; Enzymun-Test Progesterone, Roche, Meylan, France). The correlation between plasma progesterone $(\mathbf{P} 4)$ concentration and $\% \mathrm{~N}$ was tested. The $\mathrm{P} 4$ measurement was dichotomized at $3.2 \mathrm{nmol} / \mathrm{L}(1 \mathrm{ng} /$ $\mathrm{mL}$ ) (Battocchio et al., 1999) and then compared in subgroups of cows regarding the $\% \mathrm{~N}$ in endometrial and endocervical specimens.

\section{Management of the Cows}

Cows were managed according to the usual practices in their respective herds, independently of the results of the cytological evaluation. Cows were AI based solely on estrous detection, after a voluntary waiting period of 50 DIM. Treatments (hormones or antibiotics), if any, were prescribed without knowledge of the results of the cytological examinations. Pregnancy diagnosis was performed between 30 and $45 \mathrm{~d}$ after AI by transrectal ultrasonography (Aquila, Pie Medical, Hospimedi, Poisy, France). When nonpregnant, cows were re-inseminated. Culling was decided by the farmers alone based on economic considerations, without knowledge of the results of the cytological examinations. 


\section{Statistical Analyses}

Data analyses were conducted with SAS software (version 9.2, SAS Institute Inc., Cary, NC,). All $P$ values were 2 -tailed, and the $\alpha$ error was set at $5 \%$. Survival analysis, using Kaplan-Meier curves and the Cox proportional hazard model (Cox, 1972), evaluated the hazard of pregnancy within 300 DIM. Log rank tests were used for comparison of survival curves. The time variable was the interval in days between calving and conception or date of censoring, whichever came first. Because the effect of either endocervical or endometrial inflammation on the probability of pregnancy was assessed within the first 300 DIM, the survival time was censored at 300 DIM, or at the date of culling if culling occurred before 300 DIM. Multivariable Cox models provided hazard ratios that quantified the association between endocervical (or endometrial) inflammation and hazard of pregnancy. Inflammatory status was defined according to the $\% \mathrm{~N}$ in endometrial (or endocervical) specimens over the total number of cells counted and was included in the Cox model as a binary variable defined according to a threshold point (see below). Besides inflammatory status, these models included variables mentioned in the literature as being associated with pregnancy status as well as for potential confounders (i.e., variables associated with both inflammatory status and time to pregnancy, with $P$-values $<0.20$ in 1-risk factor survival analyses). Potential confounding variables examined were parity, calving difficulty, herd, and BCS. The numbers of occurrences of twin birth and of postpartum diseases were too low ( $\mathrm{n}=12$ and $\mathrm{n}=13$, respectively) to be adjusted for. Calving difficulty was not associated with either endocervical, or endometrial inflammation ( $P=0.44$ and $P=0.76$, respectively). Therefore, the multivariable models included parity (primiparous vs. multiparous), herd, and BCS ( $<2.5$ vs. $\geq 2.5$ ).

Because of a significant interaction between DIM at examination (i.e., the time elapsed between calving and collection of cytological samples) and inflammatory status (Kasimanickam et al., 2004; Galvao et al., 2009), the analysis was stratified based on DIM at examination $(<35$ vs. $\geq 35$ DIM). The threshold point for $\% \mathrm{~N}$ was selected among potential threshold points ranging from 0 to $15 \%$ (with 1 percentage point increments) as that leading to the lowest value of the Akaike information criterion (Akaike, 1974; Remontet et al., 2007) provided by the Cox model. In total, 4 multivariable Cox models were performed to define threshold points for endocervical and endometrial inflammation, respectively, before and after 35 DIM. Briefly, Akaike information criterion values are useful indicators of goodness-of-fit of statistical models and permit model selection and determination of threshold values (Remontet et al., 2007; Florescu et al., 2008; Ha et al., 2009). PROC LIFETEST and PROC PHREG SAS procedures were used for Kaplan-Meier curves and Cox proportional hazard models, respectively.

The Bland-Altman graphical method (Bland and Altman, 1986) was applied to investigate the agreement between inflammatory status of the 2 parts of the genital tract (cervix vs. uterine body), by plotting the difference between the $\% \mathrm{~N}$ in the 2 sites for each subject against their mean. Additionally, the plot includes the line for the mean difference and the experimentally observed 1.96 SD limits of the differences between the cytological examinations (commonly called limits of agreement). The Bland-Altman approach consisted of a comparison of the limits of agreement with a clinically acceptable difference between the 2 sites of inflammation. Briefly, the smaller the range between these 2 limits, the better the agreement. Moreover, the discrepancies between the 2 values are illustrated by the magnitude of the mean difference. Finally, for quantitative variables, medians were compared, and then tested, using the Wilcoxon test (or Kruskal-Wallis when $>2$ medians), and for qualitative variables, a rank-based Spearman correlation was used.

\section{RESULTS}

\section{Endocervical Inflammation}

In endocervical specimens, neutrophils represented the major cell type among leukocytes (median, 100\%; range $0-100 \%$ of total leukocytes). The proportion of neutrophils was correlated to the proportion of total leukocytes (Spearman coefficient, $\rho=0.98 ; P<0.01$ ). The median $\% \mathrm{~N}$ over the total cellular count (200 cells) was $2 \%$ (range 0-93\%). Lymphocytes were scarce (me-

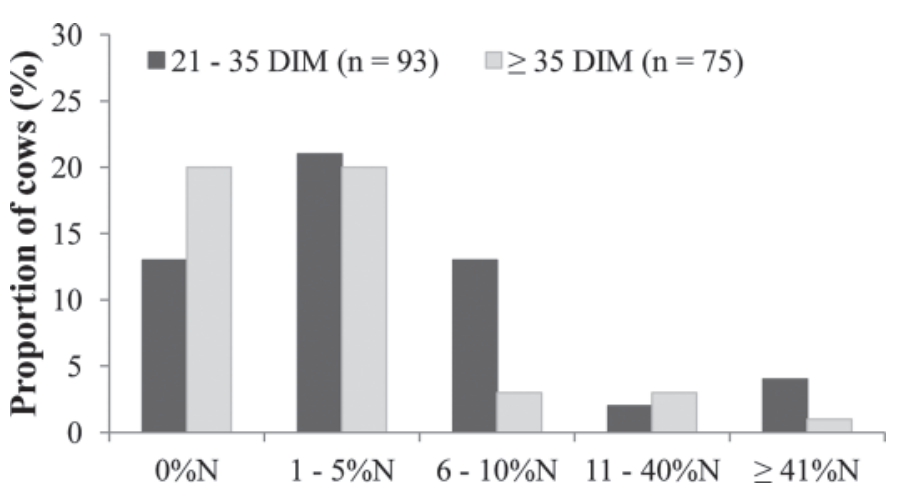

Figure 1. Percentage distribution of endocervical neutrophils $(\% \mathrm{~N})$ over the total number of cells counted according to DIM $(\mathrm{n}=$ 168 specimens). 
Table 1. Adjusted hazard ratios for the risk of pregnancy within 300 DIM, according to percentage of neutrophils $(\% \mathrm{~N})$ in endocervical specimens between 21 and 35 DIM $(\mathrm{n}=93)$

\begin{tabular}{lccc}
\hline Variable $^{1}$ & $\begin{array}{c}\text { Hazard } \\
\text { ratio }\end{array}$ & $95 \%$ CI & $P$-value \\
\hline Parity (multiparous vs. primiparous) & 1.2 & $0.7-2.2$ & 0.473 \\
BCS $(\geq 2.5$ vs. $<2.5)$ & 2.5 & $1.3-4.5$ & 0.004 \\
Herds & & & \\
Herd 1 & 1 & & \\
Herd 2 & 0.8 & $0.2-3.2$ & 0.693 \\
Herd 3 & 0.4 & $0.2-0.7$ & 0.003 \\
Endocervical inflammation $(\geq 5 \% \mathrm{~N}$ vs. $<5 \% \mathrm{~N})$ & 0.4 & $0.3-0.8$ & 0.003 \\
\hline
\end{tabular}

${ }^{1} P$-value for the overall variable "herd": $P=0.0033$.

dian, $0 \%$; range $0-7 \%$ ); monocytes (median, $0 \%$; range $0-15 \%$ ) and eosinophils (median, $0 \%$; range $0-7 \%$ ) were almost never observed.

Neutrophils were absent in $30 \%$ of the smears $(23 \%$ before 35 DIM vs. $39 \%$ after 35 DIM; Figure 1). The median percentage of endocervical neutrophils was affected by the presence of bacteria: medians were higher when free $(2 \% \mathrm{~N}$; range $0-93 \% \mathrm{~N} ; \mathrm{n}=66)$ or intracellular bacteria $(18 \% \mathrm{~N}$; range $14-93 \% \mathrm{~N} ; \mathrm{n}=11)$ were found in the specimens than when they were absent $(1 \% \mathrm{~N}$; range $0-80 \% \mathrm{~N} ; \mathrm{n}=97, P<0.01)$. Bacteria were visible in $41 \%$ of the specimens. Percentages of monocytes and lymphocytes were not associated with bacterial contamination. Percentage of endocervical neutrophils was independent of plasma $\mathrm{P} 4$ concentration (median, $3.5 \%$, range $1-93 \%$ when $\mathrm{P} 4 \geq 3.2 \mathrm{nmol} / \mathrm{L}$ vs. median, $3.5 \%$, range $=0-83 \%$ when $\mathrm{P} 4<3.2 \mathrm{nmol} / \mathrm{L} ; P=0.34$ ), but it was affected by the time elapsed since calving: cows examined before 35 DIM $(\mathrm{n}=93)$ had a higher $\% \mathrm{~N}$ (median, 3\%; range 1-93\%) than cows examined after 35 DIM ( $=75$; median, $1 \%$; range $0-89 \%$; $P<$ 0.01 ; Figure 1).

When DIM $<35$, the lowest $\% \mathrm{~N}$ presenting the minimal Akaike information criterion value in a Cox's proportional hazard model was $5 \% \mathrm{~N}$. An inflammatory level of $5 \% \mathrm{~N}$ or more in an endocervical smear was associated with a significantly lower hazard to pregnancy on any day, after adjustment for parity, BCS, and herd (adjusted hazard ratio, 0.4; 95\% CI: 0.3-0.8;
$P=0.0027$, Table 1). With the threshold of $5 \% \mathrm{~N}$, the prevalence of endocervical inflammation (cervicitis) was $42 \%$ (95\% CI: 40-50\%) in cows examined before 35 DIM. For DIM $\geq 35$, no threshold point associated with hazard of pregnancy could be determined.

\section{Endometrial Inflammation-Concordance with Endocervical Inflammation}

In endometrial specimens, the threshold point for $\% \mathrm{~N}$ for cows examined before 35 DIM was $6 \%$, with an adjusted hazard ratio for risk of pregnancy within 300 DIM of 0.4 (95\% CI: $0.2-0.7 ; P=0.0006$, Table 2). Above this threshold, the prevalence of endometrial inflammation (endometritis) was $45 \%$ (95\% CI: 40-50\%). For DIM $\geq 35$, no threshold point for the endometrial $\% \mathrm{~N}$ associated with impaired chances of pregnancy appeared.

The median percentage of leukocytes in endocervical specimens $(2 \%$; range $0-96 \%)$ was lower than that in endometrial specimens (6\%; range $0-97 \%$; $P<0.01$ ). The Bland-Altman method indicated a mean difference in $\% \mathrm{~N}$ between uterine and endocervical specimens of $7 \%$ with $95 \%$ limits of agreement of -48 to $63 \%$ (Figure 2).

Among cows affected by endocervical inflammation, $75 \%(30 / 40)$ suffered from endometrial inflammation (Table 3). Conversely, $71 \%(30 / 42)$ of cows with endometritis were affected by cervicitis. Finally, 24\% (22/93)

Table 2. Adjusted hazard ratios for the risk of pregnancy within 300 DIM, according to percentage of neutrophils $(\% \mathrm{~N})$ in endometrial specimens between 21 and 35 DIM $(\mathrm{n}=93)$

\begin{tabular}{lccc}
\hline Variable $^{1}$ & $\begin{array}{c}\text { Hazard } \\
\text { ratio }\end{array}$ & $95 \% \mathrm{CI}$ & $P$-value \\
\hline Parity (multiparous vs. primiparous) & 1.4 & $0.8-2.4$ & 0.292 \\
BCS ( $\geq 2.5$ vs. $<2.5)$ & 2.6 & $1.4-4.7$ & 0.002 \\
Herds ${ }^{\text {Herd } 1}$ & & & \\
Herd 2 & 1 & & \\
Herd 3 & 0.6 & $0.1-2.5$ & 0.478 \\
Uterine inflammation $(\geq 6 \% \mathrm{~N}$ vs. $<6 \% \mathrm{~N})$ & 0.4 & $0.2-0.8$ & 0.005 \\
\hline
\end{tabular}

${ }^{1} P$-value for the overall variable "herd": $P=0.0050$. 


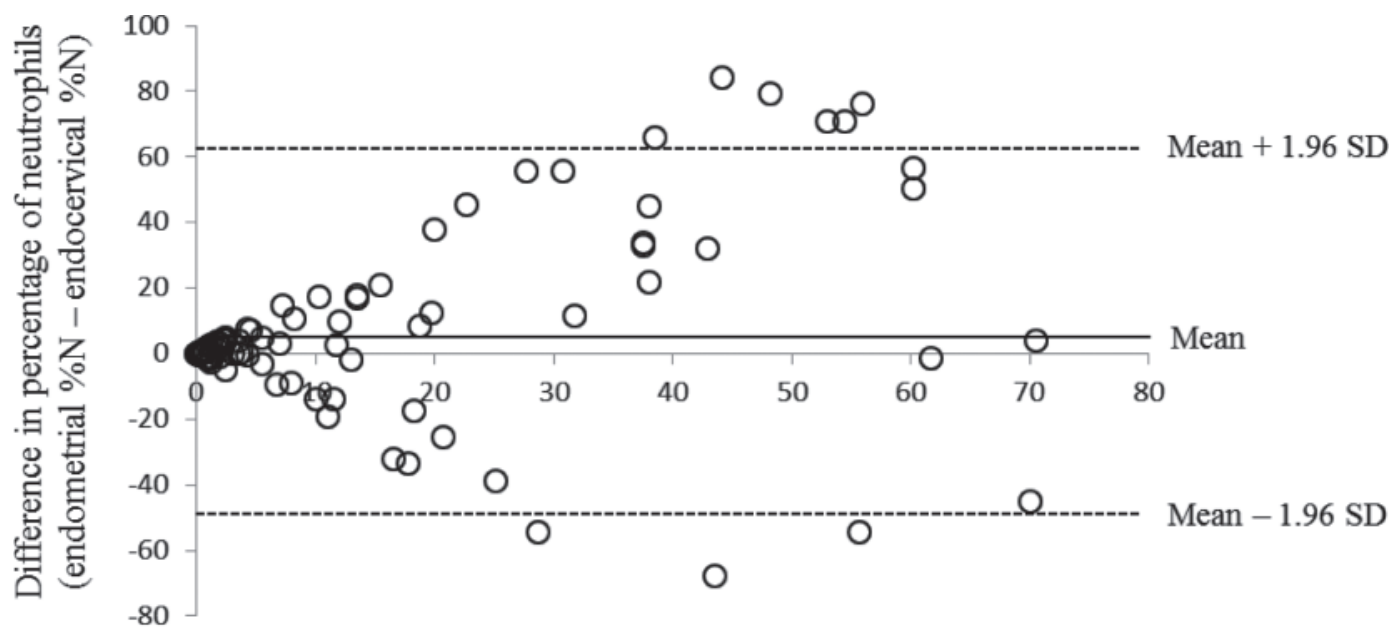

\section{Average percentage of neutrophils from endocervical and endometrial specimens}

Figure 2. Bland-Altman plot of the data of the percentage of neutrophils $(\% \mathrm{~N})$ in endometrial and endocervical specimens for each cow (n $=93)$.

of cows had only 1 compartment inflamed, $56 \%$ (52/93)

had at least 1 compartment inflamed, and 32\% (30/93) exhibited inflammation in both sites before 35 DIM.

\section{Effect of Cervicitis or Endometritis on the Hazard of Pregnancy}

Depending on the genital inflammatory status before 35 DIM, the median time to pregnancy was 125 DIM [interquartile rate (IQR): 78-160 DIM] for healthy cows, 149 DIM (IQR: 97-230 DIM) for cows suffering from endocervicitis only, 144 DIM (IQR: 124-203 DIM) for cows with endometritis only, and 154 DIM (IQR: 100-172 DIM) for cows affected by inflammation in both sites. Kaplan-Meier curves (Figure 3) using the previously selected thresholds indicated an overall association between location of genital inflammation and time to pregnancy $\left(P_{\text {logrank }}=0.0013\right)$. A relationship between genital health status and the hazard of pregnancy was suggested by the Cox's proportional hazard model adjusted for parity, BCS, and herd (Table 4). Healthy

Table 3. Distribution of cows according to percentage of neutrophils $(\% \mathrm{~N})$ in endometrial and endocervical specimens between 21 and 35 DIM $(\mathrm{n}=93)$

\begin{tabular}{lccc}
\hline & \multicolumn{2}{c}{ Endometrial cytology } & \\
\cline { 2 - 3 } $\begin{array}{l}\text { Endocervical } \\
\text { cytology }\end{array}$ & $<6 \% \mathrm{~N}$ & $\geq 6 \% \mathrm{~N}$ & Total \\
\hline$<5 \% \mathrm{~N}$ & 41 & 12 & 53 \\
$\geq 5 \% \mathrm{~N}$ & 10 & 30 & 40 \\
Total & 51 & 42 & 93 \\
\hline
\end{tabular}

cows had a significantly higher pregnancy rate (hazard) compared with cows affected by combined endometrial and endocervical inflammation (adjusted hazard ratio, 3.4; 95\% CI: $1.8-6.7 ; P=0.0003$, Table 4).

\section{DISCUSSION}

The cervix, composed of a series of mucosal-lined collagenous rings, is one of the major anatomical barriers protecting the uterus from pathogens in the environment (Dhaliwal et al., 2001; Sheldon and Dobson, 2004; Azawi, 2008). The cervical mucus functions as a biological and physical barrier against germs that may otherwise ascend the reproductive tract from the lower genital tract (Sheldon and Dobson, 2004). Conversely, because of its anatomical position, the cervix is exposed to inflammation generated by luminal debris and bacteria expelled by uterine contractions (Dhaliwal et al., 2001).

The present work is the first to include cytological examination for the specific evaluation of endocervical inflammatory status in dairy cows. Our study provides clear evidence that the number of days to conception of dairy cows is affected not only by endometrial inflammation, but also by endocervical inflammation, as diagnosed by cytology. Even though a deleterious effect of cytobrush sampling cannot be ruled out, such samplings repeated every 3 or $4 \mathrm{~d}$ for $30 \mathrm{~d}$ in another study (Deguillaume et al., 2010) did not induce any increase in neutrophil infiltration in the uterus or cervix.

The proportion of neutrophils that represent the major leukocyte subpopulation in both endocervical and 
Table 4. Adjusted hazard ratios for the risk of pregnancy within 300 DIM, according to location of the cytological inflammation between 21 and 35 DIM $(\mathrm{n}=93)$

\begin{tabular}{lccc}
\hline Variable $^{1}$ & $\begin{array}{c}\text { Hazard } \\
\text { ratio }\end{array}$ & $95 \%$ CI & $P$-value \\
\hline Parity (multiparous vs. primiparous) & 1.4 & $0.8-2.5$ & 0.292 \\
BCS ( $\geq 2.5$ vs. $<2.5)$ & 2.6 & $1.4-4.8$ & 0.002 \\
Herds & & & \\
Herd 1 & 1 & & 0.572 \\
Herd 2 & 0.65 & $0.2-2.9$ & 0.005 \\
Herd 3 & 0.4 & $0.2-0.8$ & \\
Cytological inflammation & & & 0.134 \\
EC and EM inflammations & 1 & & 0.053 \\
EM inflammation & 2.0 & $0.8-5.0$ & 0.0003 \\
EC inflammation & 2.7 & $1.0-7.2$ & \\
No inflammation & 3.4 & $1.8-6.7$ &
\end{tabular}

${ }^{1} \mathrm{EC}=$ endocervical inflammation $(\geq 5 \%$ neutrophils on endocervical specimens $) ; \mathrm{EM}=$ endometrial inflammation ( $\geq 6 \%$ neutrophils on endometrial specimens).

endometrial specimens was predictive of hazard to pregnancy. In view of the decrease in the median percentage of neutrophils and the decrease in the critical threshold with time elapsed since calving (Kasimanickam et al., 2004; Galvão et al., 2009; Gautam et al., 2010), the data were stratified based on day at examination ( $<35$ vs. $\geq 35$ DIM). Only inflammation prior to 35 DIM affected fertility, whereas no influence of inflammation observed after 35 DIM was observed, regardless of the genital compartment examined, in contrast to other studies
(Kasimanickam et al., 2004; Gilbert et al., 2005; Dubuc et al., 2010a). Considering endometrial inflammation prior to 35 DIM after adjustment for parity, BCS, and herd, the hazard of pregnancy was decreased when $\% \mathrm{~N}$ exceeded $6 \%$. This threshold supports the literature for cows examined before 35 DIM, with published thresholds from 6 to $8 \% \mathrm{~N}$ (Baranski et al., 2009; Galvão et al., 2009; Dubuc et al., 2010a). Unlike in Ahmadi et al. (2006a), this threshold was unaffected by the endocrine environment. For endocervical inflammation, a thresh-

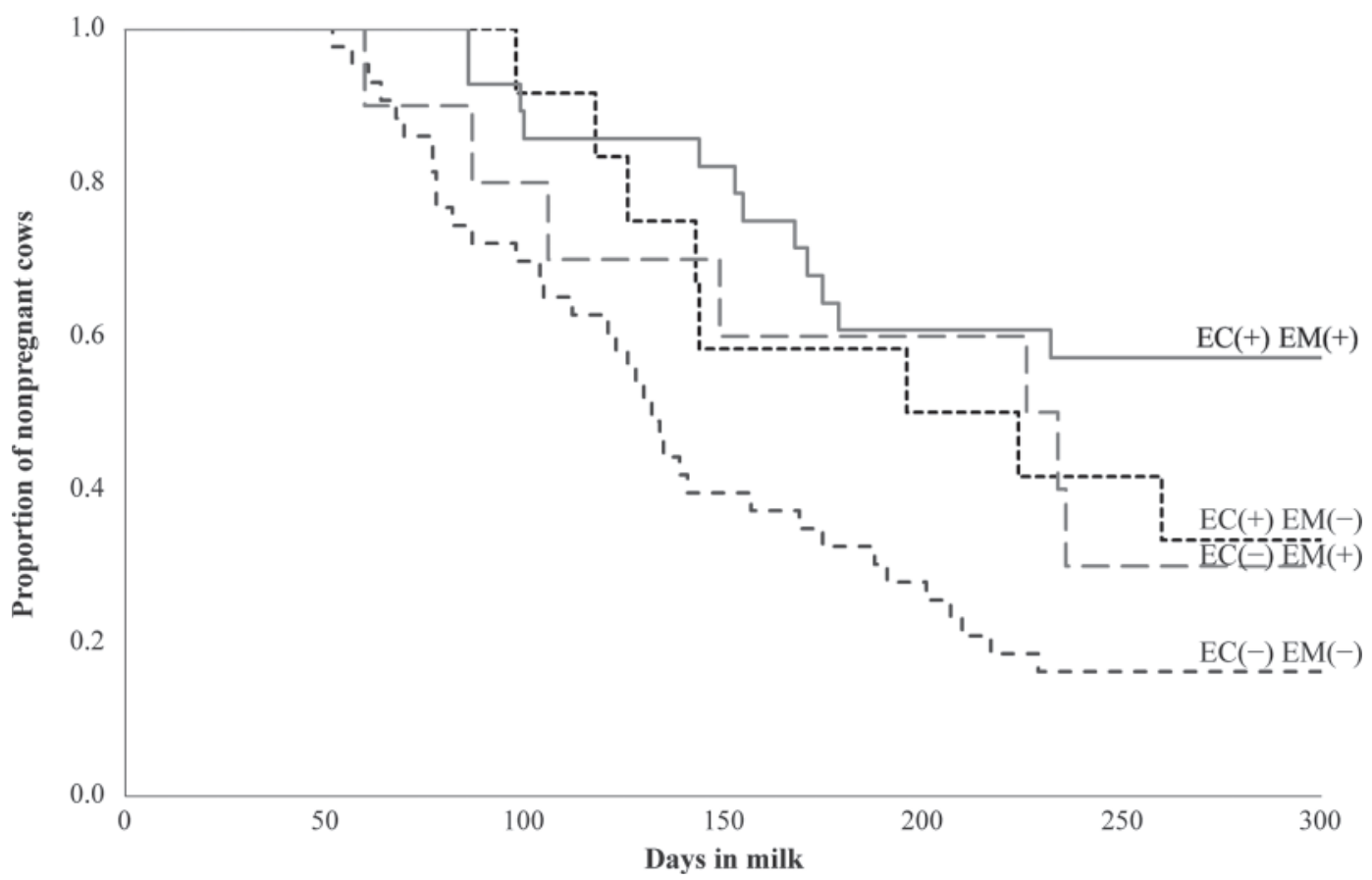

Figure 3. Kaplan-Meier curves for proportions of nonpregnant cows according to the percentage of neutrophils (\%N) from each part of genital tract $(\mathrm{n}=93$ cows examined between 21 and $35 \mathrm{DIM}) . \mathrm{EC}(-) \mathrm{EM}(-)=$ no inflammation (i.e., $<5 \% \mathrm{~N}$ in endocervical specimen, and $<6 \% \mathrm{~N}$ in endometrial specimen); $\mathrm{EC}(-) \mathrm{EM}(+)=$ endometrial inflammation (i.e., $\geq 6 \% \mathrm{~N}$ in endometrial specimen and $<5 \% \mathrm{~N}$ in endocervical specimen); $\mathrm{EC}(+) \operatorname{EM}(-)=$ endocervical inflammation (i.e., $\geq 5 \% \mathrm{~N}$ in endocervical specimen and $<6 \% \mathrm{~N}$ in endometrial specimen); $\mathrm{EC}(+)$ $\operatorname{EM}(+)=$ both inflammations (i.e., $\geq 5 \% \mathrm{~N}$ in endocervical specimen and $\geq 6 \% \mathrm{~N}$ in endometrial specimen). 
old of $5 \% \mathrm{~N}$ was determined, very close to that found in the same cows for uterine inflammation. Stephens et al. (1986) proposed a threshold for endocervical inflammation at $5 \% \mathrm{~N}$, based on similarity with endometrial inflammation, but without demonstration.

Beyond the negative effect on days to conception of endocervical inflammation by itself, our study indicates an additive effect of endocervical and endometrial inflammation on subsequent hazard of pregnancy. Cervicitis was regarded as a cause of vaginal discharge, leading to an overestimation of endometritis in the field. Because vaginitis, cervicitis, and endometritis are all expressed clinically by a purulent discharge, it is difficult to evaluate the proportion of subclinical cervicitis, as well as the contribution of each compartment, to the production of vaginal pus (Dubuc et al., 2010a,b). Few studies have attempted to evaluate the prevalence of cervicitis and its effect on bovine reproduction. Among 1,000 cases of failure to conceive, Gloor (1967) diagnosed 126 cows affected by clinical cervicitis, defined by an edema of the cervical os, associated with mucosal congestion, enlargement, hardening of the cervix, and presence of pus flecks in the vagina. Gonzalez et al. (1985) reported that $44 \%$ of nonpregnant cows were affected by cervicitis, diagnosed by histological examination. Based on our cytological definition, the prevalence of cytological cervicitis during the postpartum period was high (42\%). Most (75\%) of these cases of cervicitis were associated with cytological endometritis (Table $3)$. Nevertheless, the investigation of the difference between $\% \mathrm{~N}$ in both specimens by the Bland-Altman graphical method (Figure 2) revealed a lack of concordance between inflammatory status of the endometrial and endocervical mucosae, because the observed magnitude of difference is clinically important. Cervicitis and endometritis appear as separate conditions, albeit sometimes related. The direction of initiation of inflammation between these 2 compartments has not been described. Nevertheless, it can be assumed that the origin of the cervical contamination may be not only uterine but also vaginal. The cervix, playing a role of physical barrier for the uterus (Azawi, 2008), may become inflamed by ascending infection from the vagina and the environment, in the absence of endometrial inflammation. Conversely, cervical relaxation allows bacteria and inflammatory cells (from the bacterial contamination of the uterus immediately after calving) to be expelled from the uterus, extending inflammation from the endometrium to the endocervical mucosa. Ahmadi et al. (2006a,b) reported no significant difference between polymorphonuclear cell percentages in cervical and uterine mucosa, and thus proposed endocervical cytology as an easy-to-perform alternative for diagnosis of endometritis in cows and in ewes (Ahmadi et al., 2006a). Nevertheless, $29 \%$ of cows affected by cytological endometritis were not affected by cervicitis. As a consequence, endocervical cytology cannot be proposed as a valid alternative to endometrial sampling for the diagnosis of endometritis.

Because cervicitis was not associated with endometritis in $25 \%$ of cows, the decrease in fertility with cervicitis is not necessarily related to the effect of endometrial inflammation. Cervicitis between 21 and 35 DIM may eventually induce subsequent inflammation of the upper genital tract. Endometrial inflammation can be detected at mating or in case of repeated insemination failure (Wendt et al., 2006; Kaufmann et al., 2009). Moreover, an inflamed cervix may be responsible for blood contamination of the uterine body during passage of the cervix required for $\mathrm{AI}$, and thus alter the success of AI.

\section{CONCLUSIONS}

Although little studied, postpartum cervicitis in dairy cows should be investigated because of its high prevalence and significant effect on hazard of pregnancy. Long regarded only as a physical barrier protecting the uterus, the cervix may have to be evaluated separately during the postpartum period for prediction of subsequent reproductive success. It may be advisable to substitute the concept of "genital health" for that of the currently accepted "uterine health" to encompass inflammation in both compartments, uterus and cervix. The mechanism linking endocervical inflammation with delay to conception may be of interest for therapy and should be explored.

\section{ACKNOWLEDGMENTS}

The authors acknowledge Intervet-Schering Animal Health (Beaucouzé, France) for funding this project. We express our gratitude to Marc Chodkiewicz for careful review of the manuscript. We also thank the owners and staff of the participating herds.

\section{REFERENCES}

Ahmadi, M. R., S. Nazifi, and H. R. Ghaisari. 2006a. Comparative cervical cytology and conception rate in postpartum dairy cows. Veterinarski Arhiv 76:323-332.

Ahmadi, M. R., S. Nazifi, and H. R. Ghaisari. 2006b. Comparison of hormonal changes of oestrus cycle with cytology of cervical mucosa and hematological parameters in dairy heifers. Comp. Clin. Pathol. 15:94-97.

Akaike, H. 1974. A new look at the statistical model identification. IEEE Trans. Automat. Contr. 19:716-723.

Azawi, O. I. 2008. Postpartum uterine infection in cattle: A review. Anim. Reprod. Sci. 105:187-208.

Baranski, W., M. Podhalicz-Dziegielewska, T. Janowski, S. Zdunczyk, and G. Ukazewicz. 2009. Preliminary cytological and bacterio- 
logical findings in post-partum uterus of cows. Reprod. Domest. Anim. 44:95.

Barlund, C. S., T. D. Carruthers, C. L. Waldner, and C. W. Palmer. 2008. A comparison of diagnostic techniques for postpartum endometritis in dairy cattle. Theriogenology 69:714-723.

Battocchio, M., G. Gabai, A. Mollo, M. C. Veronesi, F. Soldano, G. Bono, and F. Cairoli. 1999. Agreement between ultrasonographic classification of the corpus luteum and plasma progesterone concentration in dairy cows. Theriogenology 51:1059-1069.

Bland, J. M., and D. G. Altman. 1986. Statistical methods for assessing agreement between two methods of clinical measurement. Lancet 1(8476):307-310.

Couto, M. A., and J. P. Hughes. 1984. Technique and interpretation of cervical and endometrial cytology in the mare. J. Equine Vet. Sci. $4: 265-273$.

Cox, D. R. 1972. Regression models and life tables. J. R. Stat. Soc. B 34:187-220.

Deguillaume, L., C. Pineau, H. Choukroun, R. Fournier, and S. Chastant-Maillard. 2010. Influence of the oestrus cycle stage on postpartum endometrial inflammation in the cow. Reprod. Domest. Anim. 45(Suppl. 3):61

Dhaliwal, G. S., R. D. Murray, and Z. Woldehiwet. 2001. Some aspects of immunology of the bovine uterus related to treatments for endometritis. Anim. Reprod. Sci. 67:135-152.

Dubuc, J., T. F. Duffield, K. E. Leslie, J. S. Walton, and S. J. LeBlanc 2010a. Definitions and diagnosis of postpartum endometritis in dairy cows. J. Dairy Sci. 93:5225-5233.

Dubuc, J., T. F. Duffield, K. E. Leslie, J. S. Walton, and S. J. LeBlanc. 2010b. Randomized clinical trial of antibiotic and prostaglandin treatments for uterine health and reproductive performance in dairy cows. J. Dairy Sci. 93:5764-5771.

Edmonson, A. J., I. J. Lean, L. D. Weaver, T. Farver, and G. Webster. 1989. A body condition scoring chart for Holstein cows. J. Dairy Sci. $72: 68-78$

Florescu, M., B. Hasan, L. Seymour, K. Ding, and F. A. Shepherd. 2008. A clinical prognostic index for patients treated with erlotinib in National Cancer Institute of Canada Clinical Trials Group study BR.21. J. Thorac. Oncol. 3:590-598.

Galvão, K. N., M. Frajblat, S. B. Brittin, W. R. Butler, C. L. Guard, and R. O. Gilbert. 2009. Effect of prostaglandin $\mathrm{F}_{2 \alpha}$ on subclinical endometritis and fertility in dairy cows. J. Dairy Sci. 92:49064913.

Gautam, G., T. Nakao, K. Koike, S. T. Long, M. Yusuf, R. M. Ranasinghe, and A. Hayashi. 2010. Spontaneous recovery or persistence of postpartum endometritis and risk factors for its persistence in Holstein cows. Theriogenology 73:168-179.
Gilbert, R. O., S. T. Shin, C. L. Guard, H. N. Erb, and M. Frajblat. 2005. Prevalence of endometritis and its effects on reproductive performance of dairy cows. Theriogenology 64:1879-1888.

Gloor, H. 1967. Cervicitis als Sterilitätsursache. Schweiz. Arch. Tierheilkd. 109:574-579.

Gonzalez, H. E., W. A. Crowell, A. B. Caudle, and F. N. Thompson. 1985. Morphometric studies of the bovine uterus: Microscopic lesions and retrospective reproductive history. Am. J. Vet. Res. $46: 2588-2595$

Ha, J., J. Yoon, and H. Kim. 2009. Relationship between winter temperature and mortality in Seoul, South Korea, from 1994 to 2006. Sci. Total Environ. 407:2158-2164.

Jones, M. L., and R. W. Allison. 2007. Evaluation of the ruminant complete blood cell count. Vet. Clin. North Am. Food Anim. Pract. 23:377-402.

Kasimanickam, R., T. F. Duffield, R. A. Foster, C. J. Gartley, K. E. Leslie, J. S. Walton, and W. H. Johnson. 2004. Endometrial cytology and ultrasonography for the detection of subclinical endometritis in postpartum dairy cows. Theriogenology 62:9-23.

Kaufmann, T. B., M. Drillich, B. A. Tenhagen, D. Forderung, and W. Heuwieser. 2009. Prevalence of bovine subclinical endometritis 4h after insemination and its effects on first service conception rate. Theriogenology 71:385-391.

Kramer, J. W. 2000. Normal hematology of cattle, sheep and goats. Pages 1075-1084 in Schalm's Veterinary Hematology. B. F. Feldman, J. G. Zinkl, and N. C. Jain, ed. Lippincott Williams and Wilkins, Philadelphia, PA.

LeBlanc, S. J. 2008. Postpartum uterine disease and dairy herd reproductive performance: A review. Vet. J. 176:102-114.

Remontet, L., N. Bossard, A. Belot, and J. Esteve. 2007. An overall strategy based on regression models to estimate relative survival and model the effects of prognostic factors in cancer survival studies. Stat. Med. 26:2214-2228.

Sheldon, I. M., and H. Dobson. 2004. Postpartum uterine health in cattle. Anim. Reprod. Sci. 82-83:295-306.

Sheldon, I. M., E. J. Williams, A. N. Miller, D. M. Nash, and S. Herath. 2008. Uterine diseases in cattle after parturition. Vet. J. 176:115-121.

Stephens, L. R., K. J. Slee, P. Poulton, M. Larcombe, and E. Kosior. 1986. Investigation of purulent vaginal discharge in cows, with particular reference to Haemophilus somnus. Aust. Vet. J. 63:182-185.

Wendt, H., H. Zerbe, H. W. Michelmann, H. J. Schuberth, and D. Raph. 2006. Immunological response in the bovine uterus after artificial insemination. Reprod. Domest. Anim. 41:40. (Abstr.) 